\title{
The Brief Core Schema Scales (BCSS): psychometric properties and associations with paranoia and grandiosity in non-clinical and psychosis samples
}

\author{
DAVID FOWLER ${ }^{1 *}$, DANIEL FREEMAN ${ }^{2}$, BEN SMITH $^{3}$, ELIZABETH KUIPERS $^{2}$, \\ PAUL BEBBINGTON ${ }^{3}$, HANNAH BASHFORTH ${ }^{4}$, SIAN COKER ${ }^{1}$, JOANNE \\ HODGEKINS ${ }^{1}$, ALISON GRACIE ${ }^{2}$, GRAHAM DUNN ${ }^{4}$ AND PHILIPPA GARETY ${ }^{2}$ \\ ${ }^{1}$ University of East Anglia, Norwich, UK; ${ }^{2}$ Institute of Psychiatry, King's College London, London, UK; \\ ${ }^{3}$ University College London, London, UK; ${ }^{4}$ University of Manchester, Manchester, UK
}

\begin{abstract}
Background. Traditional instruments that measure self-esteem may not relate directly to the schema construct as outlined in recent cognitive models. The Brief Core Schema Scales (BCSS) aim to provide a theoretically coherent self-report assessment of schemata concerning self and others in psychosis. The scales assess four dimensions of self and other evaluation: negative-self, positive-self, negative-other, positive-other.
\end{abstract}

Method. We analysed the psychometric properties of the BCSS using a sample of 754 students recruited by email and 252 people with psychosis recruited as part of a trial of cognitive therapy. We report the internal consistency, stability and the factor structure of the scale, and the association of the BCSS with measures of self-esteem and with symptoms of paranoia and grandiosity.

Results. The BCSS have good psychometric properties and have more independence from mood than the Rosenberg Self-Esteem Schedule. People with chronic psychosis reported extreme negative evaluations of both self and others on these scales, but their levels of self-esteem and positive evaluations of self and others were similar to the student sample.

Conclusions. Extreme negative evaluations of self and others appear to be characteristic of the appraisals of people with chronic psychosis, and are associated with symptoms of grandiosity and paranoia in the non-clinical population. The BCSS may provide a more useful measure of schemata about self and others than traditional measures of self-esteem.

\section{INTRODUCTION}

The way in which people make judgements or evaluate themselves and other people may be a central process mediating their adaptation to the social world. Such evaluations probably form part of a basic human response to social stresses and threats, and thus may be associated with the complex range of biological, cognitive, and behavioural reactions that characterize

\footnotetext{
* Address for correspondence: Professor David Fowler, School of Medicine, Health Policy and Practice, Elizabeth Fry Building, University of East Anglia, Norwich NR4 7TJ, UK.

(Email: D.fowler@uea.ac.uk)
}

emotional responses (Gilbert, 1992; Brown et al. 1995). Many recent cognitive theories of both psychotic and non-psychotic psychiatric disorders suggest that moment-to-moment evaluations of self and others may be linked to current external events, current mood and cognitive state, and to memory processes in the form of schema that synthesize past reactions (Beck, 1976; Gilbert, 1992; Teasdale \& Barnard, 1993). Such models can thus provide a coherent psychological explanation for the way in which past and current social stresses and emotional reactions are mediated by ongoing appraisals. Such constructs were originally associated most 
closely with theories of depression (Beck, 1976; Teasdale \& Barnard, 1993; Clark et al. 1999), but have also been incorporated into current theories of PTSD (Foa \& Rothbaum, 1998; Dalgleish, 1999; Ehlers \& Clark, 2000; Brewin, 2003) and eating disorders (Fairburn et al. 2003). Negative evaluations of self and others have also been incorporated into models of paranoia and persecutory delusions (Chadwick et al. 1996; Bentall et al. 2001; Freeman et al. 2002; Bentall \& Swarbrick, 2003), hallucinations (Close \& Garety, 1998; Fowler, 2000; Beck \& Rector, 2003) and delusions (Fowler, 2000; Garety et al. 2001). There is still considerable debate about the exact nature and significance of the schema construct and different cognitive theories may have competing hypotheses. Further research in this important area would be advanced by the development of a more specific assessment tool.

In a recent study, Barrowclough et al. (2003), using a detailed interview assessment of selfesteem, showed specific and differential associations between negative personal evaluations (described as negative character deficits) and positive psychotic symptoms. Other types of evaluations of self were not associated with positive psychotic symptoms. This study provides support for the use of a measure of self and other evaluation that is focused on a specific aspect of self-appraisal, namely extreme negative evaluations of self which may be regarded as an assessment of negative self-schema. However, the self-esteem interview is very detailed, and this precludes its use in large-scale clinical studies.

A variety of existing questionnaires have been used to assess self-esteem and self-appraisals in psychosis (e.g. Rosenberg, 1965; Robson, 1988; Young, 1990; Brown et al. 1995; Schmidt et al. 1995; Freeman et al. 1998; Perris et al. 1998; Beck et al. 2001); however, few of these instruments provide a direct assessment of the negative self-evaluation construct consistent with contemporary schema constructs as applied to psychosis. Furthermore some, such as the Rosenberg Self-Esteem Schedule (RSES), have outdated norms and poor psychometric adequacy (Keith \& Bracken, 1996). Our aim was to develop a scale that would provide a quick and easily administered measure of negative evaluations of self (negative self-schema) but also of positive evaluations of self and positive and negative evaluations of others. Different aspects of self and other evaluation may be associated with different types of psychotic symptom (Fowler et al. 1995; Fowler, 2000; Garety et al. 2001). Several cognitive accounts of paranoia emphasize that the evolution of negative evaluations of others (e.g. evaluations that others are untrustworthy, bad, devious) may be as important in understanding paranoia either alone or in combination with evaluations of self (Trower \& Chadwick, 1995; Fowler, 2000; Garety et al. 2001). However, grandiose delusions may represent exaggerated positive evaluations of self (Fowler et al. 1995). We therefore designed the new instrument to assess positive and negative evaluations of self and positive and negative evaluations of others. The negative evaluation of self component of the present scale derives from the Depressed States Checklist (Teasdale \& Dent, 1987; Teasdale \& Cox, 2001), and therefore has item content which reflects an already well established concept of negative schematic models of self. The scale also has conceptual similarities to the existing Evaluative Beliefs Scale (Chadwick et al. 1999); however, while the negative self dimension of both scales is similar, the negativeother scale of the Brief Core Schema Scales (BCSS) is different, as it represents appraised threat from others (e.g. others are untrustworthy, devious) rather than appraised hostility or dominance (e.g. other people are worthless, inferior) as assessed in the Evaluative Beliefs Scale. The present scale is also the only existing scale to assess positive evaluations of self and others in combination with negative evaluations of self and others. The resultant fourdimensional structure is consistent theoretically with the widely used four-group attachment styles framework proposed by Bartholomew \& Horowitz (1991). This may be an advantage in developing hypotheses linking schema in psychosis with attachment theory in future work.

In the present study we report basic psychometric properties of the BCSS in non-clinical and clinical samples, including internal consistency, stability, item factor analysis, and concurrent reliability with the RSES and subscales of Young's Schema Questionnaire (YSQ). To assess the validity of the scale we tested hypotheses implying differential associations between 
self and other evaluations and the occurrence of different types of symptoms in the student sample. In accordance with the predictions of our cognitive model of psychosis (Fowler et al. 1995; Fowler, 2000; Garety et al. 2001) we hypothesized that paranoia would be associated with a combination of negative beliefs about self, negative beliefs about others, and anxiety, whereas grandiosity would be associated with positive evaluations of self and others and not with negative evaluations of others. We also describe a comparison of norms in the student sample compared with a sample of 252 cases with chronic psychotic illness who were recruited for a trial of cognitive behavioural therapy. We hypothesized that the students and cases with psychotic illness would show similar levels of self-esteem on the RSES and positive evaluations of self and others, but that the sample of people with psychotic illness would specifically show extreme negative evaluations of self and others in comparison to the students.

\section{METHOD}

\section{Non-clinical sample}

Eight hundred and fifty-six students were recruited from King's College London and University College London. Participants were emailed the address of a website where they could complete the questionnaires online. Sixtyfive per cent were female, $35 \%$ male, $70 \%$ were White, 17\% Asian, 2\% Afro-Caribbean, 1\% African and $10 \%$ of other ethnic origin. Mean age was 23.6 years $($ S.D. $=6 \cdot 5)$. In all, 754 students completed all items, which included version A and version B of the BCSS. A further 257 students were recruited from University of East Anglia and King's College London, to undertake a study of test-retest reliability of the Schema questionnaires online. These participants repeated the schema questionnaires 3 weeks apart (mean 21 days, s.D. $=7$ days).

\section{Psychosis sample}

A sample of 252 people with psychosis was drawn from the cohort of patients recruited for the Psychological Prevention of Relapse in Psychosis (PRP) Trial (ISRCTN83557988). All those who completed the Schema questionnaire at the initial baseline assessment constitute the sample for this study. The PRP Trial is a
UK multi-centre randomized controlled trial of cognitive behaviour therapy and family intervention for psychosis, designed to answer questions both about outcome and the psychological processes associated with psychosis. Studies of psychological processes in psychosis are incorporated into the baseline assessment of participating patients before randomization into the trial takes place. The trial was located in four NHS trusts in London and East Anglia: the South London and Maudsley NHS Trust; Norfolk Mental Health NHS Trust; Camden \& Islington Mental Health and Social Care NHS Trust; and North East London Mental Health NHS Trust. Recruitment was from specified clinical teams, both in-patient and out-patient services, within each of these trusts. Patients were recruited at the time of a relapse into positive symptoms. The inclusion criteria were: current diagnosis of non-affective psychosis (schizophrenia, schizoaffective psychosis, delusional disorder; ICD-10 F20); age 18-65 years; second or subsequent episode starting not more than 3 months before individuals consent to enter the trial; and rated at least 4 (moderate severity) on the Positive and Negative Syndrome Scale (PANSS) on at least one positive psychotic symptom at the first time of meeting.

\section{Measures}

\section{The Brief Core Schema Scales}

The BCSS have 24 items concerning beliefs about the self and others that are assessed on a five-point rating scale (0-4). Four scores are obtained: negative-self (six items), positiveself (six items), negative-others (six items) and positive-others (six items) (see Appendix). The content of the negative-self component derived from self-devaluative words used by Teasdale \& Dent (1987) and subsequently by Teasdale \& Cox (2001) as globally negative selfdescriptors of personality. The other items were generated by the first two authors of this paper on the basis of clinical experience with paranoia. In the original version A (see Appendix) (used in both the clinical and non-clinical samples), the individual was asked to indicate in a dichotomous $\mathrm{No} /$ Yes format whether they held each belief. Then, if they held the belief (i.e. answered yes), they were asked to indicate their degree of belief conviction by circling a number from 
1 to 4 (believe it slightly, believe it moderately, believe it very much, believe it totally).

In the non-clinical sample only, we assessed two versions of the scale. In version $\mathrm{B}$, the order of the items was randomized and a simple 0-4 Likert scale was used (there was no Yes/No response in version B). Scores on both scales were similarly distributed and the two versions of the scale also correlated very highly. For the positive-self, negative-self, positive-other, and negative-other scales, the correlations were 0.75 , $0 \cdot 74,0.70$, and 0.61 respectively. Furthermore, the pattern of results from the two scales in terms of internal consistency, factor analysis, and associations with demographics and psychopathology were very similar. In general, the associations between the BCSS and other measures were slightly stronger in all analyses for version $\mathrm{A}$. We therefore only report the results of the analysis of version $\mathrm{A}$, as this version had a clearer dimensional structure, and was the version used in both the clinical and non-clinical studies. The measure is very brief, taking only an average of 1 minute 25 seconds (s.D. $=4$ seconds) to complete. There was no association between the time to complete the measure and the scores.

\section{Rosenberg Self-Esteem Scale (Rosenberg, 1965)}

The RSES is a 10-item, four-point scale (1-4) that assesses current levels of global self-esteem. The total score is usually used. A high total score is indicative of low global self-esteem. The Rosenberg self-esteem scale is probably the most widely used self-esteem measure, although it has been criticized recently over its psychometric properties (Keith \& Bracken, 1996).

\section{Young's Schema Questionnaire - Short Version (YSQ-S; Young, 1998)}

The YSQ-S is a 75-item self-report inventory designed to assess 15 types of core schematic beliefs. The YSQ-S derives from the original YSQ (305 items). We did not administer the whole YSQ-S because of its length. Instead six key schemas that we predicted would relate to subscales of the BCSS were selected. These were: mistrust/abuse, social isolation; defectiveness/shame; failure; self-sacrifice; and entitlement. Each schema is assessed by five items, each rated on a six-point Likert scale from 1 (strongly disagree) to 6 (strongly agree).
Higher scores indicate greater endorsement of a schema.

\section{Depression Anxiety Stress Scales (DASS; Lovibond \& Lovibond, 1995)}

We used the depression and anxiety scales of this measure. Each scale consists of 14 items with a $0-3$ scale $(0=$ did not apply to me at all, $3=$ applied to me very much). Higher scores indicate higher levels of emotional distress. Lovibond \& Lovibond (1995) report results of a comparison of the DASS with the Beck Depression (BDI) and Anxiety (BAI) inventories in a non-clinical sample $(n=717)$. The DASS anxiety scale correlated at 0.81 with the BAI and the DASS depression scale correlated at 0.74 with the BDI. The authors report Cronbach's alpha internal consistency coefficients of 0.91 and 0.81 for the DASS depression and anxiety scales respectively. A principal components analysis showed a good distinction between the depression and anxiety factors of the DASS. The scale has also recently been shown to be reliable and valid in a large UK non-clinical population.

\section{Paranoia Scale (PS; Fenigstein \& Vanable, 1992)}

The 20-item self-report Paranoia Scale was developed to measure paranoia in college students, and includes items assessing both ideas of persecution and reference. The Paranoia Scale is the most widely used dimensional measure of paranoia and was derived from items in the Minnesota Multiphasic Personality Inventory (MMPI). Fenigstein \& Vanable (1992) report good internal consistency (based on a total student sample of 581) and a Cronbach's alpha of 0.84 and test re-test reliability (based on a 6-month re-test, $n=107$ ) of $0 \cdot 70$, indicating good stability over time. The authors report good norms on their student sample, with a mean score of $42 \cdot 7$ (range 20-100).

\section{The Peters et al. Delusions Inventory (PDI; Peters et al. 1999)}

Two items assessing grandiosity were used from this measure of delusional ideation. The two items were: (1) Do you ever feel as if you are or are destined to be someone very important? and (2) Do you ever feel that you are a very special 
or unusual person? Each item was rated on the following scale: 0 'never feel it', 1 'feel it rarely', 2 'feel it sometimes', 3 'feel it often', 4 'feel it most of the time', 5 'feel it all the time'. A total score from the two items was used, with higher scores indicating higher levels of grandiosity.

The questionnaires were presented on the website in the following order: BCSS questionnaire (0-4 Likert scale), RSES, YSQ subscales, DASS, PS, and the PDI grandiosity items.

\section{Statistical analysis}

Analyses were conducted using SPSS for Windows (version 11.0; SPSS, 2003). All variables were approximately normally distributed except for negative self-evaluation, which was positively skewed. Analyses were conducted using both log-transformed negative selfevaluation scores and the original scores. As the transformation did not alter results appreciably, the results for the analyses using the original scores are reported. Significance test results are quoted as two-tailed probabilities. Reliability analysis was conducted by first assessing alpha coefficients, and item whole correlations. A principal components analysis with varimax rotation is reported for the BCSS. As the components could be assumed to be correlated, both oblique and orthogonal rotations were used. However, similar solutions were found, and the orthogonal solution using varimax rotation is reported for ease of interpretation. Associations between the BCSS and the other scales and measures of psychopathology were examined, first using bivariate Pearson correlations. This was followed by standard multiple regression analyses predicting paranoia and grandiosity as a function of other emotions and schema. The aim was to assess the degree to which the BCSS explained variance in paranoia and grandiosity independently of depression and self-esteem. Where independent variables have a bivariate correlation but lack significance in the regression, their relationship with the dependent variable can be assumed to be made redundant or mediated by the other variables. Assessments of significance and significance of semi-partial correlations are therefore equivalent to forcing entry of a series of other variables in the final step in stepwise multiple regression. We chose a conservative significance level of $p<0.001$ to assess the significance of independent variables
Table 1. Means and standard deviations for all variables in the non-clinical sample

\begin{tabular}{lrrrr}
\hline \hline & Min. & Max. & Mean & S.D. \\
\hline Age $(n=747)$ & 16 & 65 & $23 \cdot 70$ & $6 \cdot 66$ \\
RSES total $(n=753)$ & 10 & 39 & $20 \cdot 85$ & $6 \cdot 04$ \\
DASS anxiety total $(n=753)$ & 0 & 41 & $7 \cdot 05$ & $7 \cdot 28$ \\
DASS depression total $(n=753)$ & 0 & 42 & $9 \cdot 62$ & $9 \cdot 46$ \\
Paranoia scale total $(n=753)$ & 20 & 91 & $41 \cdot 14$ & $14 \cdot 60$ \\
PDI grandiosity total $(n=753)$ & 0 & 10 & $4 \cdot 55$ & $2 \cdot 55$ \\
BCSS positive-self $(n=754)$ & 0 & 20 & $10 \cdot 20$ & $4 \cdot 23$ \\
BCSS negative-self $(n=754)$ & 0 & 23 & $3 \cdot 55$ & $3 \cdot 55$ \\
BCSS positive-other $(n=754)$ & 0 & 22 & $10 \cdot 43$ & $4 \cdot 51$ \\
BCSS negative-other $(n=754)$ & 0 & 22 & $4 \cdot 07$ & $4 \cdot 04$ \\
& & & & \\
\hline \hline
\end{tabular}

RSES, Rosenberg Self-Esteem Schedule; DASS, Depression Anxiety Stress Scales; PDI, Peters et al. Delusions Inventory; BCSS, Brief Core Schema Scales.

within the multiple regression in order to take account of the number of significance tests undertaken.

\section{RESULTS}

\section{Sample description}

Table 1 provides the means and standard deviations for variables in the non-clinical sample. There was a preponderance of females $(65 \%)$. The levels of depression, anxiety, paranoia and grandiosity were as expected for a nonclinical group.

The mean age of the psychosis group was 38 years (S.D. $=10)$. There were more male $(n=181$; $72 \%)$ than female $(n=71 ; 28 \%)$ participants. The group comprised the following ethnicities: White $(n=187)$, Black-African $(n=19)$, BlackCaribbean $(n=19)$, Indian $(n=5)$, other $(n=$ $19)$. The diagnoses were schizophrenia $(n=217)$, schizoaffective disorder $(n=35)$, and delusional disorder $(n=3)$. Of the sample, $88 \%$ were single or divorced and 30 were married $(12 \%)$. The mean length of illness was 11.7 years (S.D. $=$ $10 \cdot 1$ ), and $82 \%$ were unemployed, with small numbers in full-time employment $(6 \%)$. Fiftyfive per cent of the sample reported persecutory delusions, $57 \%$ auditory hallucinations, and $17 \%$ grandiose delusions.

\section{Internal consistency}

The alpha coefficients for version $\mathrm{A}$ of the positive- and negative-self-schema scales for the non-clinical and clinical samples respectively were: $0.78(0.79)$ and $0.86(0.84)$, and, for the 
Table 2. Dimensionality of the Brief Core Schema Scales: initial eigenvalues from a principal components analysis

\begin{tabular}{|c|c|c|c|c|c|c|}
\hline \multirow[b]{2}{*}{ Component } & \multicolumn{3}{|c|}{ Non-clinical sample $(n=752)$} & \multicolumn{3}{|c|}{ Chronic psychosis sample $(n=252)$} \\
\hline & Total & $\%$ of variance & Cumulative $\%$ & Total & $\%$ of variance & Cumulative $\%$ \\
\hline Negative-other & $7 \cdot 2$ & $29 \cdot 9$ & $29 \cdot 9$ & $6 \cdot 1$ & $25 \cdot 5$ & $25 \cdot 5$ \\
\hline Positive-other & $3 \cdot 2$ & $13 \cdot 4$ & $43 \cdot 3$ & $3 \cdot 8$ & $15 \cdot 8$ & $41 \cdot 3$ \\
\hline Positive-self & $2 \cdot 0$ & $8 \cdot 5$ & $51 \cdot 7$ & $2 \cdot 6$ & $10 \cdot 8$ & $52 \cdot 2$ \\
\hline Negative-self & $1 \cdot 3$ & $5 \cdot 3$ & $57 \cdot 0$ & $1 \cdot 4$ & $5 \cdot 9$ & $58 \cdot 0$ \\
\hline
\end{tabular}

Table 3. Component loading in the Brief Core Schema Scales

\begin{tabular}{|c|c|c|c|c|c|c|c|c|}
\hline \multirow[b]{2}{*}{ BCSS item } & \multicolumn{2}{|c|}{$\begin{array}{l}\text { Component } 1 \text { : } \\
\text { negative-others }\end{array}$} & \multicolumn{2}{|c|}{$\begin{array}{l}\text { Component } 2 \text { : } \\
\text { positive-others }\end{array}$} & \multicolumn{2}{|c|}{$\begin{array}{l}\text { Component } 3 \text { : } \\
\text { positive-self }\end{array}$} & \multicolumn{2}{|c|}{$\begin{array}{c}\text { Component } 4 \text { : } \\
\text { negative-self }\end{array}$} \\
\hline & $\begin{array}{l}\text { Non- } \\
\text { clinical } \\
\text { sample }\end{array}$ & $\begin{array}{l}\text { Chronic } \\
\text { psychosis } \\
\text { sample }\end{array}$ & $\begin{array}{l}\text { Non- } \\
\text { clinical } \\
\text { sample }\end{array}$ & $\begin{array}{l}\text { Chronic } \\
\text { psychosis } \\
\text { sample }\end{array}$ & $\begin{array}{l}\text { Non- } \\
\text { clinical } \\
\text { sample }\end{array}$ & $\begin{array}{l}\text { Chronic } \\
\text { psychosis } \\
\text { sample }\end{array}$ & $\begin{array}{l}\text { Non- } \\
\text { clinical } \\
\text { sample }\end{array}$ & $\begin{array}{l}\text { Chronic } \\
\text { psychosis } \\
\text { sample }\end{array}$ \\
\hline I am unloved & $0 \cdot 21$ & - & $-0 \cdot 10$ & $-0 \cdot 28$ & $-0 \cdot 16$ & $0 \cdot 28$ & 0.54 & $0 \cdot 58$ \\
\hline I am worthless & - & - & $-0 \cdot 15$ & - & $-0 \cdot 30$ & - & 0.69 & $0 \cdot 81$ \\
\hline I am weak & $0 \cdot 21$ & $0 \cdot 23$ & - & - & $-0 \cdot 24$ & $-0 \cdot 25$ & $0 \cdot 61$ & $0 \cdot 62$ \\
\hline I am vulnerable & $0 \cdot 26$ & $0 \cdot 45$ & $-0 \cdot 15$ & - & $-0 \cdot 11$ & - & 57 & $0 \cdot 42$ \\
\hline I am bad & $0 \cdot 30$ & - & - & - & $-0 \cdot 17$ & - & $0 \cdot 48$ & $0 \cdot 69$ \\
\hline I am a failure & - & $0 \cdot 28$ & - & - & - & $-0 \cdot 37$ & 0.67 & $0 \cdot 68$ \\
\hline I am respected & - & - & $0 \cdot 28$ & 0.47 & $0 \cdot 68$ & $0 \cdot 51$ & $-0 \cdot 22$ & - \\
\hline I am valuable & - & - & $0 \cdot 19$ & $0 \cdot 3$ & $0 \cdot 78$ & $0 \cdot 75$ & $-0 \cdot 14$ & - \\
\hline I am talented & - & - & - & - & $0 \cdot 79$ & 0.75 & - & $-0 \cdot 2$ \\
\hline I am successful & - & - & $0 \cdot 23$ & - & $0 \cdot 68$ & 0.73 & $-0 \cdot 27$ & - \\
\hline I am good & - & - & $0 \cdot 16$ & $0 \cdot 28$ & $0 \cdot 57$ & 0.53 & $-0 \cdot 23$ & $-0 \cdot 37$ \\
\hline I am interesting & - & - & $0 \cdot 14$ & - & $0 \cdot 77$ & $0 \cdot 8$ & - & $-0 \cdot 21$ \\
\hline Others are hostile & 0.77 & $0 \cdot 75$ & $-0 \cdot 14$ & - & - & - & $0 \cdot 11$ & - \\
\hline Others are harsh & 0.78 & 0.76 & $-0 \cdot 12$ & - & - & - & $0 \cdot 14$ & - \\
\hline Others are unforgiving & 0.72 & 0.67 & $-0 \cdot 14$ & - & - & - & $0 \cdot 11$ & $0 \cdot 3$ \\
\hline Others are bad & 0.78 & 0.69 & - & - & - & - & - & - \\
\hline Others are devious & $0 \cdot 72$ & $0 \cdot 87$ & $-0 \cdot 21$ & - & - & - & $0 \cdot 17$ & - \\
\hline Others are nasty & $0 \cdot 81$ & $0 \cdot 8$ & $-0 \cdot 12$ & - & - & - & $0 \cdot 11$ & - \\
\hline Others are fair & - & - & $0 \cdot 76$ & 0.72 & $0 \cdot 12$ & - & - & - \\
\hline Others are good & $-0 \cdot 13$ & - & 0.73 & 0.78 & $0 \cdot 16$ & - & - & - \\
\hline Others are trustworthy & $-0 \cdot 19$ & - & 0.78 & 0.71 & $0 \cdot 15$ & - & $-0 \cdot 13$ & - \\
\hline Others are accepting & $-0 \cdot 13$ & - & $0 \cdot 70$ & 0.69 & $0 \cdot 19$ & $0 \cdot 32$ & $-0 \cdot 10$ & - \\
\hline Others are supportive & $-0 \cdot 1$ & - & 0.69 & $0 \cdot 72$ & $0 \cdot 27$ & - & $-0 \cdot 11$ & - \\
\hline Others are truthful & $-0 \cdot 14$ & $-0 \cdot 3$ & $0 \cdot 77$ & $0 \cdot 70$ & $0 \cdot 16$ & - & $-0 \cdot 18$ & - \\
\hline
\end{tabular}

Factor items in bold.

positive- and negative-other schema scales: $0 \cdot 88$ $(0 \cdot 84)$ and $0 \cdot 88(0 \cdot 87)$ respectively. All item total correlations were highly significant $(p<0 \cdot 001)$. The median item total correlation was 0.74 $(0 \cdot 76)$.

\section{Dimensionality}

A principal components analysis with varimax rotation was performed on the combined scale of 24 items for both clinical and nonclinical samples. Initial eigenvalues from the analysis are shown in Table 2, and the rotated varimax component loadings matrix for a four-component solution in Table 3. A fourcomponent solution was indicated by the scree plot and eigenvalues. This solution accounted for $57 \%$ and $58 \%$ of the variance in the non-clinical and clinical samples respectively. The four-component solution corresponded to negative-other, positive-other, positive-self, and negative-self subscales in both samples.

\section{Concurrent and discriminant validity}

Table 4 shows bivariate Spearman's correlations between BCSS subscales and the YSQ subscales and RSES in the non-clinical sample. The 
Table 4. Spearman's bivariate correlations between Brief Core Schema subscales and the Young's Schema Questionnaire subscales and Rosenberg Self-Esteem Schedule in non-clinical sample

\begin{tabular}{llllc}
\hline \hline & Positive-self & Negative-self & Positive-other & Negative-other \\
\hline YSQ mistrust/abuse & $-0 \cdot 32$ & $0 \cdot 40$ & $-0 \cdot 51$ & $0 \cdot 49$ \\
YSQ social isolation & $-0 \cdot 39$ & $0 \cdot 45$ & $-0 \cdot 41$ & $0 \cdot 28$ \\
YSQ defective/shame & $-0 \cdot 53$ & $0 \cdot 44$ & $-0 \cdot 35$ & $0 \cdot 20$ \\
YSQ failure & $-0 \cdot 24$ & $0 \cdot 15$ & $-0 \cdot 17$ & $0 \cdot 18$ \\
YSQ self-sacrifice & $0 \cdot 06$, N.S. & $0 \cdot 06$, N.S. & $-0 \cdot 16$ & $0 \cdot 16$ \\
RSES total score & $-0 \cdot 59$ & $0 \cdot 53$ & $-0 \cdot 39$ & $0 \cdot 23$ \\
Depression & $-0 \cdot 45$ & $0 \cdot 63$ & $-0 \cdot 41$ & $0 \cdot 29$ \\
Anxiety & $-0 \cdot 33$ & $0 \cdot 5$ & $-0 \cdot 34$ & $0 \cdot 30$ \\
\hline \hline
\end{tabular}

YSQ, Young's Schema Questionnaire; RSES, Rosenberg Self-Esteem Schedule. $p<0 \cdot 001$ unless specified non-significant (N.S.).

BCSS had moderate to strong associations with the RSES and with the defectiveness/shame, mistrust/abuse and social isolation Young subscales. There were only very low associations between the BCSS and Young's failure and self-sacrifice scales. In the psychosis sample the RSES and negative- self and positive-self subscales had a moderate to strong association ( $r=0.64$ and $0.65, p<0.001$ respectively). Correlations between the RSE and BCSS negative-other and positive-other scales in the clinical sample were weak $(r=0 \cdot 2$ and $-0 \cdot 26$, $p<0 \cdot 001$, respectively).

\section{Stability}

The stability of the scales was assessed in the non-clinical sample by test-retest reliability of scales taken by a sample of 257 students on two occasions approximately 3 weeks apart (mean 21 days, s.D. $=7$ ). Test-retest reliability (Pearson's $r$ ) for the negative-self, positive-self, negative-other and positive-other scales respectively were $r=0.84,0.82,0.7$ and 0.72 (all significant $p<0 \cdot 001)$.

\section{Associations with demographic variables}

There were no associations between the BCSS and age, sex or years in education in the nonclinical sample. In the sample of people with psychosis there was no association between age, sex or length of illness and the BCSS scales. However, the subgroup of 30 married people with psychosis tended to have more extreme negative self-evaluation than unmarried people $(t=-2 \cdot 9$, df $207, p<0 \cdot 005)$ and less positive self-evaluation than unmarried people $(t=2 \cdot 2$, df 206, $p<0 \cdot 05$ ).

\section{Associations with paranoia and grandiosity (non-clinical sample)}

A standard multiple regression was undertaken, with paranoia as the dependent variable and depression, anxiety, the RSES and the BCSS as the explanatory variables. The adjusted $R$ square was $0 \cdot 51$. $R$ was highly significant $[F(7,744)=110 ; \quad p<0.0001]$. Four variables contributed significantly to the prediction of paranoia. These were, as predicted, in order of importance, negative-other (bivariate $r=0.57$; $\left.s r^{2}=0.31 ; t=12.2 ; p<0.0001\right)$, positive-other (bivariate $r=-0.49 ; s r^{2}=-0.2 ; t=-7 \cdot 7 ; p<$ $0 \cdot 0001$ ), anxiety (bivariate $r=0.48 ; s r^{2}=0.13$; $t=5.2 ; p<0.0001$ ) and negative-self (bivariate $\left.r=0.5 ; s r^{2}=0.09 ; t=1.9 ; p<0.0001\right)$. This suggests that the negative-other scale explains approximately $9 \%$ of the variance in paranoia, independently of the other variables. Low positive-other scores may account for another $4 \%$ and anxiety another $2 \%$ respectively. Around $30 \%$ of the variability in paranoia was explained by common variance between the variables. Depression and the Rosenberg selfesteem scores contributed no unique variance to paranoia, and apparent bivariate associations between depression $(0.48)$ and the Rosenberg self-esteem scores $(0 \cdot 4)$ and paranoia were made redundant by or mediated by other variables.

A standard multiple regression undertaken with grandiosity as the dependent variable, and anxiety, depression, paranoia, the Rosenberg self-esteem schedule and the BCSS as explanatory variables provided an adjusted $R$ square of $0 \cdot 3$. $R$ was highly significant $(F=40 \cdot 3 ; p<$ $0 \cdot 001)$. Two variables contributed significantly to grandiosity at the $p<0.001$ level. These were 


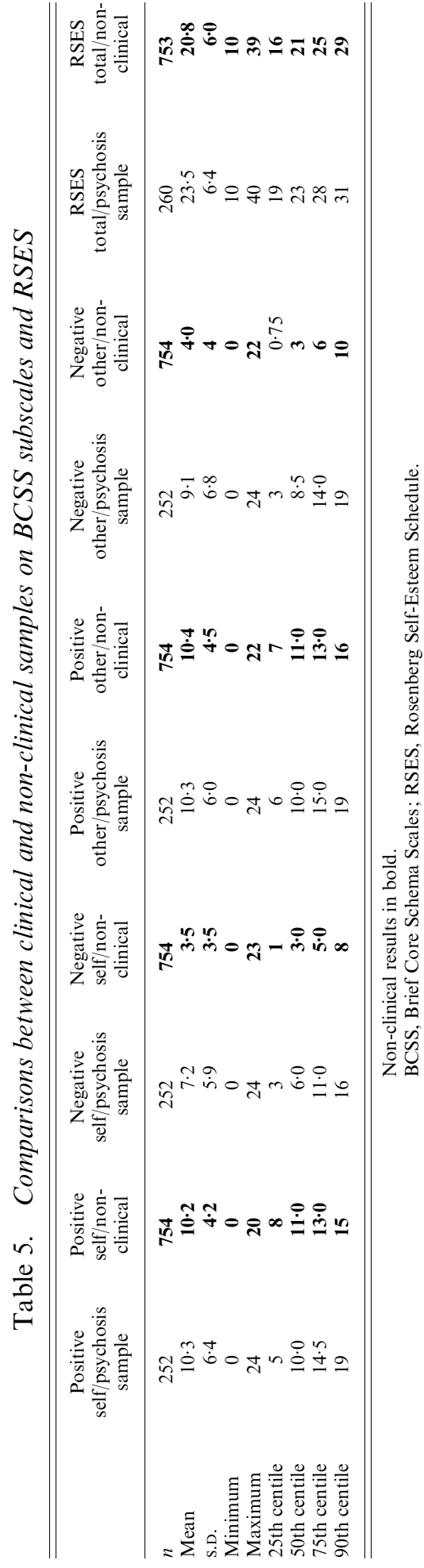

positive-self (bivariate $r=0.4 ; s r^{2}=0.37 ; t=$ $12 \cdot 1 ; p<0 \cdot 001$ ) and paranoia (bivariate $r=0 \cdot 23$; $\left.s r^{2}=0.22 ; t=7 \cdot 2 ; p<0.001\right)$. Two other variables had weak trends, suggesting a small degree of unique association with grandiosity. These were positive-other (bivariate $r=-0.02 ; s r^{2}=$ $0-0.08 ; t=-2.7 ; p<0.06)$ and the RSES (bivariate $r=-0 \cdot 2 ; s r^{2}=-0.08 ; t=-2 \cdot 4 ; p=$ $0 \cdot 014)$. Fourteen per cent of the variance was explained by positive-self, a further $5 \%$ by paranoia, and less than $1 \%$ uniquely by the positive-other scores and the Rosenberg. Ten per cent of the variance was common. As predicted, neither negative-self nor negative-other scores contributed to grandiosity.

\section{Comparison of scores in the non-clinical and psychosis samples}

Table 5 shows means, standard deviataions and various centile scores for the psychosis and nonclinical samples. As expected there are clear indications that the sample of people with psychosis had extremely negative evaluations of themselves and others. The mean score of $7 \cdot 2$ in the sample of people with psychosis reflects the fact that moderate to strong endorsement of beliefs that 'I am bad, weak, worthless' etc. was common. Endorsement of negative beliefs about others (e.g. that others were 'hostile', 'harsh', 'unforgiving', 'nasty', etc.) was also common in the psychosis sample. However, endorsement of such beliefs in the student sample was rare. As predicted there were no significant differences in positive evaluations of self and others or in self-esteem as measured by the Rosenberg selfesteem schedule. Scores in the non-clinical and clinical samples in terms of positive evaluations of self were similar $[10.2$ (s.D. $=6.4)$ v. 9.4 (s.D. $=6 \cdot 9$ )] respectively, and there was also no difference in the positive evaluations of others scores $[10 \cdot 3 \quad($ S.D. $=6)$ v. $10.2 \quad($ S.D. $=6 \cdot 2)]$ respectively. These scores do not therefore indicate a lack of positive views of self and others amongst the psychosis group. Scores on the RSES between the psychosis sample (23.5, s.D. $=6 \cdot 4)$ and non-clinical samples $(20 \cdot 8$, s.D. $=6)$ were also in a similar range.

\section{DISCUSSION}

Our aim in developing this scale was to create a quick and easy-to-use assessment of the type of 
extreme positive and negative evaluations of self and others that we have observed clinically to be typical of people with psychosis. The scales we have developed have good internal consistency, and the principal components analysis suggested an underlying dimensional structure that reflects independence between different dimensions of self and other evaluation. There were differential associations between the BCSS and measures of paranoia in the non-clinical sample, as required by our cognitive model of psychotic symptoms (Fowler, 2000; Garety et al. 2001; Freeman et al. 2002). As we predicted, negative-other evaluations were strongly and uniquely associated with paranoia in the non-clinical sample, in combination with negative-self scores and anxiety. Paranoia in the non-clinical sample therefore occurs in a specific context of anxiety toned with evaluations of interpersonal threat and personal vulnerability. The role of negative self-evaluation in association with paranoia is consistent with the findings reported in a companion paper (Smith et al. unpublished observations) from an analysis of the clinical sample. Also as predicted, the positive-self score strongly and uniquely predicted grandiosity in the non-clinical sample.

The BCSS deliberately assess an extreme form of negative evaluation of self (e.g. judging oneself to be weak, worthless, useless, inadequate) and others (e.g. judging others to be bad, devious, untrustworthy). Such appraisals, if held strongly, may be viewed as core with respect to their potentially catastrophic implications for one's place in a social context. Appraising oneself as inadequate whilst appraising others as devious and bad implies a potentially very dangerous social position in which one is both weak and threatened by others. Consistent with Barrowclough and colleagues (2003) we suggested that, rather than lack of self-esteem (as measured by traditional questionnaires), it may be specifically this type of core appraisal of danger and vulnerability in a social context that is typical of people with psychosis and may be linked to paranoia and other extreme emotional and psychotic reactions (Garety et al. 2001). The comparison of a sample of students with a sample of people with chronic relapsing psychosis allows few conclusions to be drawn regarding reasons for differences between groups as the samples differ in many variables such as age, education and social circumstances, as well as symptom presence. However, the differential findings were as predicted. What was observed was that the psychotic sample had similar levels of selfesteem and positive evaluations of self and others to the student sample, but showed very extreme negative evaluations of self and others. A degree of independence between assessments of core schema and mood is suggested by associations between the BCSS and paranoia and grandiosity remaining when assessments of mood were controlled in the regression analysis. This may be an advantage in future studies. Further studies of the psychometric properties of the BCSS are needed. The preliminary studies reported here are promising but not definitive. The dimensional structure appears robust, providing similar components in both the non-clinical sample and the sample of acutely ill chronic patients. However, there is a particular need to examine the performance of the BCSS in other clinical and matched nonclinical samples, and with recovered as well as actively psychotic samples. Investigations of the stability of the tool in clinical groups are also required.

The total time taken to complete the BCSS suggests that the judgement for each item is made within seconds. While rapid, the associations with psychopathology and the other scales found in the present study suggests such evaluations are not an epiphenomena, but relate to judgements that have meaning and importance. The lack of time to reflect may imply that the reporting of self and other evaluative thinking, as assessed by the BCSS, is likely to indicate a relatively automatic judgement about self and others that comes rapidly to mind. This relative speed may be an advantage, as it may tap the person's ongoing momentto-moment evaluations of self in relation to others used habitually, rather than a process of conscious reflection that may be subject to self-presentation bias. It may relate closely to the clinical concept of 'hot cognition'.

In summary, the BCSS appear to be useful. They have both good psychometric properties and construct validity for use in studies testing hypotheses relating to schema and self and other evaluation constructs. Further studies are 
required, particularly of stability over time, but also of how such appraisals may mediate the association of trauma and stressful life events with the biological, cognitive, behavioural and emotional responses that characterize psychopathology.

\section{APPENDIX}

\section{The Brief Core Schema Scales: beliefs about self and others}

This questionnaire lists beliefs that people can hold about themselves and other people. Please indicate whether you hold each belief (NO or YES). If you hold the belief then please indicate how strongly you hold it by circling a number (1-4). Try to judge the beliefs on how you have generally, over time, viewed yourself and others. Do not spend too long on each belief. There are no right or wrong answers and the first response to each belief is often the most accurate.

\begin{tabular}{|c|c|c|c|c|c|c|c|}
\hline & & & & $\begin{array}{l}\text { Believe it } \\
\text { slightly }\end{array}$ & $\begin{array}{c}\text { Believe it } \\
\text { moderately }\end{array}$ & $\begin{array}{c}\text { Believe it } \\
\text { very much }\end{array}$ & $\begin{array}{c}\text { Believe it } \\
\text { totally }\end{array}$ \\
\hline I am unloved & NO & YES & $\rightarrow$ & 1 & 2 & 3 & 4 \\
\hline I am worthless & NO & YES & $\rightarrow$ & 1 & 2 & 3 & 4 \\
\hline I am weak & NO & YES & $\rightarrow$ & 1 & 2 & 3 & 4 \\
\hline I am vulnerable & NO & YES & $\rightarrow$ & 1 & 2 & 3 & 4 \\
\hline I am bad & NO & YES & $\rightarrow$ & 1 & 2 & 3 & 4 \\
\hline I am a failure & NO & YES & $\rightarrow$ & 1 & 2 & 3 & 4 \\
\hline I am respected & NO & YES & $\rightarrow$ & 1 & 2 & 3 & 4 \\
\hline I am valuable & $\mathrm{NO}$ & YES & $\rightarrow$ & 1 & 2 & 3 & 4 \\
\hline I am talented & NO & YES & $\rightarrow$ & 1 & 2 & 3 & 4 \\
\hline I am successful & $\mathrm{NO}$ & YES & $\rightarrow$ & 1 & 2 & 3 & 4 \\
\hline I am good & $\mathrm{NO}$ & YES & $\rightarrow$ & 1 & 2 & 3 & 4 \\
\hline I am interesting & NO & YES & $\rightarrow$ & 1 & 2 & 3 & 4 \\
\hline Other people are hostile & NO & YES & $\rightarrow$ & 1 & 2 & 3 & 4 \\
\hline Other people are harsh & $\mathrm{NO}$ & YES & $\rightarrow$ & 1 & 2 & 3 & 4 \\
\hline Other people are unforgiving & $\mathrm{NO}$ & YES & $\rightarrow$ & 1 & 2 & 3 & 4 \\
\hline Other people are bad & $\mathrm{NO}$ & YES & $\rightarrow$ & 1 & 2 & 3 & 4 \\
\hline Other people are devious & $\mathrm{NO}$ & YES & $\rightarrow$ & 1 & 2 & 3 & 4 \\
\hline Other people are nasty & NO & YES & $\rightarrow$ & 1 & 2 & 3 & 4 \\
\hline Other people are fair & $\mathrm{NO}$ & YES & $\rightarrow$ & 1 & 2 & 3 & 4 \\
\hline Other people are good & NO & YES & $\rightarrow$ & 1 & 2 & 3 & 4 \\
\hline Other people are trustworthy & NO & YES & $\rightarrow$ & 1 & 2 & 3 & 4 \\
\hline Other people are accepting & $\mathrm{NO}$ & YES & $\rightarrow$ & 1 & 2 & 3 & 4 \\
\hline Other people are supportive & NO & YES & $\rightarrow$ & 1 & 2 & 3 & 4 \\
\hline Other people are truthful & $\mathrm{NO}$ & YES & $\rightarrow$ & 1 & 2 & 3 & 4 \\
\hline
\end{tabular}

\section{ACKNOWLEDGEMENTS}

We thank all the participants who took part in the studies from both the Universities and the NHS trusts, and in addition the NHS staff who helped with recruitment. This study was supported by a Wellcome Trust Programme Grant: 062452. PRP is registered as ISRCTN: 83557988 .

\section{DECLARATION OF INTEREST}

None.

\section{REFERENCES}

Barrowclough, C., Tarrier, N., Humphreys, L., Ward, J., Gregg, L. \& Andrews, B. (2003). Self-esteem in schizophrenia: relationships between self-evaluation, family attitudes and symptomology. Journal of Abnormal Psychology 112, 92-99.

Bartholomew, K. \& Horowitz, L. M. (1991). Attachment styles among young adults: a test of a four-category model. Journal of Personality and Social Psychology 61, 226-244.

Beck, A. T. (1976). Cognitive Therapy and the Emotional Disorders. IUP: New York.

Beck, A. T. \& Rector, N. A. (2003). A cognitive model of hallucinations. Cognitive Therapy \& Research 27, 19-52.

Beck, A. T., Brown, G. K., Steer, R. A., Kuyken, W. \& Grisham, J. (2001). Psychometric properties of the Beck Self-Esteem Scales. Behaviour Research \& Therapy 39, 115124. 
Bentall, R. P., Corcoran, R., Howard, R., Blackwood, N. \& Kinderman, P. (2001). Persecutory delusions: a review and theoretical integration. Clinical Psychology Review 21, 1143-1192.

Bentall, R. \& Swarbrick, R. (2003). The best laid schemas of paranoid patients: autonomy, sociotropy and need for closure. Psychology \& Psychotherapy: Theory, Research \& Practice 76, 163-171.

Brewin, C. R. (2003). Posttraumatic Stress Disorder: Malady or Myth? Yale University Press: New Haven, CT.

Brown, G. P., Hammen, C. L., Craske, M. G. \& Wickens, T. D. (1995). Dimensions of dysfunctional attitudes as vulnerabilities to depressive symptoms. Journal of Abnormal Psychology 104, 431-435.

Brown, G. W., Harris, T. O. \& Hepworth, C. (1995). Loss, humiliation and entrapment among women developing depression: a patient and non-patient comparison. Psychological Medicine $\mathbf{2 5}$ $7-21$.

Chadwick, P. D. J., Birchwood, M. J., \& Trower, P. (1996). Cognitive Therapy for Delusions, Voices and Paranoia. Wiley: Chichester.

Chadwick, P., Trower, P. \& Dagnan, D. (1999). Measuring negative person evaluations: the Evaluative Beliefs Scale. Cognitive Therapy \& Research 23, 549-559.

Clark, D. A., Beck, A. T. \& Alford, B. A. (1999). Scientific Foundations of Cognitive Theory and Therapy of Depression. John Wiley: New York.

Close, H. \& Garety, P. A. (1998). Cognitive assessment of voices: further developments in understanding the emotional impact of voices. British Journal of Clinical Psychology 37, 173-188.

Dalgleish, T. (1999). Cognitive theories of post-traumatic stress disorder. In Post-Traumatic Stress Disorder: Concepts and Therapy (ed. W. Yule), pp. 197-212. John Wiley: New York.

Ehlers, A. \& Clark, D. M. (2000). A cognitive model of posttraumatic stress disorder. Behaviour Research \& Therapy 38 , 319-345.

Fairburn, C. G., Cooper, Z. \& Shafran, R. (2003). Cognitive behaviour therapy for eating disorders: a 'transdiagnostic' theory and treatment. Behaviour Research \& Therapy 41, 509-528.

Fenigstein, A. \& Vanable, P. A. (1992). Paranoia and selfconsciousness. Journal of Personality and Social Psychology $6 \mathbf{2}$, $129-138$.

Foa, E. B. \& Rothbaum, B. O. (1998). Treating the Trauma of Rape: Cognitive Behavioural Therapy for PTSD. Guildford: New York.

Fowler, D. (2000). Psychological formulation of early episodes of psychosis: a cognitive model. In Early Intervention in Psychosis: A Guide to Concepts, Evidence and Interventions (ed. M. Birchwood, D. Fowler and C. Jackson). John Wiley: Chichester.

Fowler, D., Garety, P. A. \& Kuipers, E. K. (1995). Cognitive Behaviour Therapy for Psychosis: Theory and Practice. John Wiley: Chichester.

Freeman, D., Garety, P. A., Fowler, D., Kuipers, E. K., Dunn, G., Bebbington, P. \& Hadley, C. (1998). The London-East Anglia randomized controlled trial of cognitive-behaviour therapy for psychosis IV: self-esteem and persecutory delusions. British Journal of Clinical Psychology 37, 415-430.

Freeman, D., Garety, P. A., Kuipers, E., Fowler, D. \& Bebbington, P. E. (2002). A cognitive model of persecutory delusions. British Journal of Clinical Psychology 41, 331-347.

Garety, P. A., Kuipers, E. K., Fowler, D., Freeman, D. \& Bebbington, P. E. (2001). A cognitive model of the positive symptoms of psychosis. Psychological Medicine 31, 189-195.

Gilbert, P. (1992). Depression: The Evolution of Powerlessness. Erlbaum: London.

Keith, L. K. \& Bracken, B. A. (1996). Self-concept instrumentation: a historical and evaluative review. In Handbook of Self-Concept: Developmental, Social, and Clinical Considerations (ed. B. A. Bracken), pp. 91-170. Oxford, UK.

Lovibond, P. F. \& Lovibond, S. H. (1995). The structure of negative emotional states: comparison of the depression anxiety stress scales (DASS) with the Beck depression and anxiety inventories. Behaviour Research and Therapy 33, 335-343.

Perris, C., Fowler, D., Lund, G. \& Skagerlind, P. (1998). The development and validation of the dysfunctional working models of the self questionnaire (DWMS): a scale to measure dysfunctional assumptions in schizophrenia and related conditions. Acta Psychiatrica Scandinavia 98, 219-223.

Peters, E. R., Joseph, S. A. \& Garety, P. A. (1999). Measurement of delusional ideation in the normal population: introducing the PDI (Peters et al. Delusions Inventory). Schizophrenia Bulletin 25 , 553-576.

Robson, P. J. (1988). Self-esteem: a psychiatric view. British Journal of Psychiatry 153, 6-15.

Rosenberg, M. (1965). Society and the Adolescent Self-Image. Princeton University Press: Princeton, USA.

Schmidt, N. B., Joiner, T. E., Young, J. E. \& Telch, M. J. (1995). The schema questionnaire: investigation of psychometric properties and the hierarchical structure of a measure of maladaptive schemas. Cognitive Therapy and Research 19, 295-321.

Teasdale, J. D. \& Barnard, P. J. (1993). Affect, Cognition, and Change: Re-modelling Depressive Thought. Lawrence Erlbaum Associates: Hove, UK.

Teasdale, J. D. \& Cox, S. G. (2001). Dysphoria: self devaluative and affective components in recovered depressed patients and never depressed controls. Psychological Medicine 31, 1311-1316.

Teasdale, J. D. \& Dent, J. (1987). Cognitive vulnerability to depression: an investigation of two hypotheses. British Journal of Clinical Psychology 26 (Pt 2), 113-126.

Trower, P. \& Chadwick, P. D. J. (1995). Pathways to defense of the self: a theory of two types of paranoia. Clinical Psychology: Science and Practice 2, 263-278.

Young, J. E. (1990). Cognitive Therapy for Personality Disorders: A Schema-Focused Approach. Professional Resource Exchange: Sarasota, FL.

Young, J. E. (1998). The Young schema questionnaire short form (http://home.sprynet.com/sprynet/schema/ysqs1.htm). Accessed 2003 . 